\title{
Use of a synthetic foot-and-mouth disease virus peptide conjugated to gold nanoparticles for enhancing immunological response
}

\author{
Lev A. Dykman ${ }^{1,2} \cdot$ Sergey A. Staroverov ${ }^{1,2}$ - Pavel V. Mezhenny ${ }^{3}$. \\ Alexander S. Fomin ${ }^{1,2} \cdot$ Sergey V. Kozlov ${ }^{3}$ Alexey A. Volkov ${ }^{3}$. \\ Vladislav N. Laskavy ${ }^{2} \cdot$ Sergei Yu. Shchyogolev ${ }^{1,4}$
}

Published online: 25 July 2015

(C) The Author(s) 2015. This article is published with open access at SpringerLink.com

\begin{abstract}
Foot-and-mouth disease is an acute, highly contagious infection of domestic and wild cloven-hoofed animals, which can be transmitted to humans. In many cases, the existing vaccines are not quite effective. The purpose of this study was to test the possibility of using gold nanoparticles as an antigen carrier and an adjuvant. The immunogenic properties of gold nanoparticles were assessed by conjugating the particles to a synthetic peptide of the $\mathrm{VP}_{1}$ capsid protein of the foot-and-mouth disease virus. The resulting conjugate (with or without the use of complete Freund's adjuvant), a commercial vaccine, and the native peptide served to immunize guinea pigs. The titer and sensitivity of the raised antibodies were maximal for the combination comprising the nanoparticle-peptide conjugate and complete Freund's adjuvant. Antibody biosynthesis was accompanied by increased production of proinflammatory cytokines (especially IFN- $\gamma$ ) and by stimulation of the respiratory activity of peritoneal macrophages. The use of gold nanoparticles as a hapten carrier enhanced the immune response even when complete Freund's adjuvant was not used.
\end{abstract}

Lev A. Dykman

dykman@ibppm.sgu.ru

1 Institute of Biochemistry and Physiology of Plants and Microorganisms, Russian Academy of Sciences, Saratov, Russia

2 Veterinary Research Institute, Russian Academy of Agricultural Sciences, Saratov, Russia

3 Saratov State Agricultural University, Saratov, Russia

4 Saratov State University, Saratov, Russia
Keywords Foot-and-mouth disease virus $\cdot$ Synthetic peptide vaccines $\cdot$ Gold nanoparticles $\cdot$ Adjuvant

\section{Introduction}

Foot-and-mouth disease (FMD) is an acute, highly contagious infection of domestic and wild cloven-hoofed animals, which can be transmitted from animals to humans. It is caused by a filterable RNA-containing aphthovirus of the family Picornaviridae. On the basis of antigenic structure, seven serotypes of the FMD virus (FMDV) have been identified, each of which includes several variants (about 80 in total) [1]. The number of recorded FMD outbreaks has been increasing significantly since the early 2010, and in Russia, there were 14 outbreaks in five regions in the first half of 2013 alone.

Vaccination is a major means of preventing FMD. For prophylactic vaccinations, various monovalent and polyvalent inactivated FMD vaccines are employed [2], but no live vaccines have so far been developed. Although existing vaccines are in many cases effective against the disease, they have several essential disadvantages: The immune response develops slowly; vaccinated animals can become infected before an immune response is generated; and animals can become virus carriers even after being successfully vaccinated [3, 4]. Furthermore, it is known that during the recent systematic FMD vaccination in Europe, up to half the disease outbreaks recorded annually have been due to "underinactivated" formulations and to their residual infectivity [5]. Therefore, the search for new vaccines is continuing, examples being the recently proposed recombinant peptide vaccines [6] and experimental procapsid and synthetic peptide vaccines [7, 8]. A search is also in progress for the most effective adjuvants [9]. 
Much work on synthetic peptide vaccines has been done with the FMDV. This became possible once it was established that the virus protein $\mathrm{VP}_{1}$, in particular a major neutralizing immunogenic site (amino acids 135-159) and an additional site near the $\mathrm{C}$ terminus of this polypeptide $[10,11]$, is responsible for the induction of FMDV-neutralizing antibodies. In Volpina et al. [12], a synthetic peptide with amino acids 135-159 of $\mathrm{VP}_{1}$ was made, which was linked to keyhole limpet hemocyanin and supplemented with Freund's adjuvant. The vaccine induced neutralizing antibodies in guinea pigs, pigs, and cattle and protected against infection with a virulent FMDV strain. However, the antibody response after immunization with the peptide was 10 times lower than that observed after immunization with whole virions. Synthetic peptides corresponding to the neutralizing epitopes of $\mathrm{VP}_{1}$ of FMDVs of three serotypes had different antigenic and immunogenic activities. Peptides specific for serotypes A and $\mathrm{O}$ induced protective immunity in guinea pigs, whereas the peptide specific for serotype $\mathrm{C}$ proved less active. Peptides with the amino acid sequences of $\mathrm{VP}_{1}$ of all seven FMDV serotypes elicited neutralizing antibodies in guinea pigs. The antibodies were mostly serotype-specific [12]. The possibility of preparing a bivalent peptide vaccine against FMD was next established by Volpina et al. [13], who synthesized two peptides for different serotypes in tandem. The dipeptide vaccines induced synthesis of neutralizing antibodies to two FMDV serotypes. A synthetic peptide corresponding to the 135-159 region of $\mathrm{VP}_{1}$ of FMDV type A was administered to guinea pigs, sheep, and cattle together with Freund's adjuvant, resulting in a high level of neutralizing antibody and resistance to infection with a homologous virulent FMDV strain. Immunity was found to depend on the affinity of the antibodies induced by the synthetic peptide. Immunization with the synthetic peptide construct ensured that experimentally infected pigs were protected against the disease [14].

There is a great current interest in using nanoparticles of various natures as platforms for vaccines [15-19]. Gold nanoparticles (AuNPs) are some of the most promising antigen carriers for immunization [20-22] owing to their adjuvant properties $[23,24]$. AuNPs were first used as part of an antiviral vaccine to carry the protein antigen of the tickborne encephalitis virus capsid [25]. Although not containing adjuvants, the proposed experimental vaccine offered better protection than did its commercial counterparts. Subsequently, AuNPs have been used to generate antibodies and design experimental vaccines (both peptide and carbohydrate) against influenza A virus [26, 27], transmissible gastroenteritis virus [28], West Nile virus [29], the respiratory syncytial virus [30], as well as against tuberculosis [31, 32] and other bacterial infections [33-37]. In addition, AuNPs are being used in the development of experimental vaccines against tumors $[38,39]$.
The purpose of this study was to investigate the possibility that AuNPs could serve as a carrier of an FMDV synthetic peptide and as an adjuvant in the immunization of animals. AuNPs were chosen because they have been employed successfully in designing prototypes of peptide vaccines against several viral and bacterial infections. In Volpina et al. [12, 13], the synthetic peptides were not coupled to a nanosized carrier, and the vaccination efficacies were insufficient. We now propose the use of peptide antigen-AuNP conjugates to improve the efficacy of vaccination.

\section{Materials and methods}

\section{Peptide antigen}

The antigen used for immunization was a lyophilized commercial synthetic peptide spanning the 135-159 region of the FMDV capsid protein $\mathrm{VP}_{1}$ (Cytokine Co., Russia). The peptide contained 25 amino acid residues [amino acid sequence, KYSAGGMGRRGDLEPLAARVAAQLP; brutto formula, $\mathrm{C}_{111} \mathrm{H}_{186} \mathrm{~N}_{36} \mathrm{O}_{33} \mathrm{~S}_{1}$; molecular mass, $2584.96 \mathrm{Da}$ (with account taken of the natural isotope content); and isoelectric point, 10.32]. The peptide was dissolved in $0.01 \mathrm{M}$ phosphate-buffered saline (PBS), $\mathrm{pH} 7.4$, to $1 \mathrm{mg} \mathrm{ml}^{-1}$.

The control was a commercial inactivated tissue culture FMD vaccine (Federal Centre for Animal Health "ARRIAH," Russia) that contained an oil adjuvant Montanide ISA 206. The amount of protein present in the commercial vaccine was estimated by the colorimetric method of Lowry [40] with a Genesys 10S UV-vis spectrophotometer (Thermo Scientific, USA).

\section{Preparation of antigen-AuNP conjugates}

Spherical AuNPs (15 nm mean diameter) were prepared according to Frens [41] by the reduction of tetrachloroauric acid (Sigma-Aldrich, USA) with sodium citrate (Fluka, Switzerland). A $242.5 \mathrm{ml}$ portion of $0.01 \%$ aqueous tetrachloroauric acid was heated to $100{ }^{\circ} \mathrm{C}$ on a magnetic stirrer in an Erlenmeyer flask fitted with a water-cooled reflux tube. This was followed by the addition of $7.5 \mathrm{ml}$ of $1 \%$ aqueous sodium citrate to the flask. The total preparation time was $45 \mathrm{~min}$.

The particle diameter was determined with a Specord S 250 UV-vis spectrophotometer (Analytik Jena, Germany), a Libra 120 transmission electron microscope (Carl Zeiss, Germany), and a Zetasizer Nano-ZS particle size and zeta potential analyzer (Malvern, UK), as described by Khlebtsov and Dykman [42].

To prepare antigen-AuNP conjugates, we determined the "gold number" (minimal amount of antigen that protects the sol against salt aggregation) for the peptide solution. To this 
end, $20 \mu \mathrm{l}$ of an antigen solution in PBS (initial concentration, $1 \mathrm{mg} \mathrm{m}^{-1}$ ) was titrated twofold on a 96-well microtiter plate. Each well received $200 \mu \mathrm{l}$ of AuNPs and $20 \mu \mathrm{l}$ of $1.7 \mathrm{M} \mathrm{NaCl}$. The minimal stabilizing concentration was determined visually by the change in the color of the AuNP solution from red to blue in the wells of a microtiter plate. The minimal stabilizing concentration for the antigen was $12.5 \mu \mathrm{g} \mathrm{ml}{ }^{-1}$. Conjugation was done by simple mixing (without the use of coupling agents) [43].

Determination of the gold number presupposes that the antigen molecules, when being adsorbed onto the AuNP surface, protect the $\mathrm{Au}$ sol against salt aggregation. If there are not enough antigen molecules to cover the particle surface, the addition of an electrolyte results in particle aggregation, giving a blue color to the solution. In our case, such an effect was observed when the antigen concentration was $6.25 \mu \mathrm{g} \mathrm{ml}^{-1}$. Thus, at the $12.5 \mathrm{\mu g} \mathrm{ml}^{-1}$ concentration, either all added peptide was adsorbed on the AuNPs or there was a slight excess of it. It should be noted that a slight excess of soluble antigen not only does not interfere with immunization but also facilitates an increase in antibody elaboration [44].

The use of a minimal stabilizing concentration presupposes that all of the peptide is conjugated to AuNPs and is almost absent from solution. Nevertheless, to remove all traces of unbound antigen, we centrifuged the conjugate at $13,000 \times g$ for $15 \mathrm{~min}$, decanted the supernatant liquid, and redissolved the pellet in PBS.

\section{Animals}

Fifteen male albino guinea pigs, weighing 300-350 g by the time the experiment started, were used in this study. Animal care and handling were in accordance with the Guide for the Care and Use of Laboratory Animals, the European Convention for the Protection of Vertebrate Animals Used for Experimental and Other Scientific Purposes, and the legislation of the Russian Federation.

\section{Immunization procedure}

For immunobiological studies, the guinea pigs were divided into five groups of three in each on the basis of their body weight (deviation of the body weight within a group, $\pm 10 \%$ ).
The animals were immunized subcutaneously at 10 points along the spinal column by two injections with an interval of 10 days between. The antigen doses used are given in Table 1 .

The guinea pigs in group 1 were injected with $0.5 \mathrm{ml}$ of the commercial vaccine according to the instructions supplied by the manufacturer. Group 2 received $1 \mathrm{ml}$ of AuNP-peptide conjugates mixed 1:1 with complete Freund's adjuvant (CFA; Becton Dickinson, USA); group 3, $1 \mathrm{ml}$ of AuNPpeptide conjugates without CFA; group 4, $1 \mathrm{ml}$ of a peptide solution in PBS mixed 1:1 with CFA; and group 5 (control), a 1.7 $\mathrm{M} \mathrm{NaCl}$ solution. Thus, group 2 received $29 \mu \mathrm{g} \mathrm{Au}$, and group 3 received $58 \mu \mathrm{g}$ Au. The animals were killed 10 days after the last injection.

\section{Isolation of peritoneal macrophages and splenic lymphocytes}

For peritoneal macrophages, the animals were killed and then fixed on their backs. An incision was made along the midline of the anterior abdominal wall, and the skin flap was carefully separated, with care taken to keep the peritoneum intact. After a puncture had been made with a needle connected to a syringe, $50 \mathrm{ml}$ of $\mathrm{PBS}, \mathrm{pH}$ 7.2, was injected into the peritoneal cavity. The anterior abdominal wall was then gently massaged, and after 5-7 min, peritoneal fluid was collected with a Pasteur pipet through a cut made in the peritoneum and was filtered into a test tube through a nylon filter. The cells were washed three times by centrifugation in PBS at $750 \times g$, after which they were redissolved in $1 \mathrm{ml}$ of PBS and counted in a Goryaev chamber. Peritoneal macrophages were cultured by standard procedures [45].

For splenic lymphocytes, an incision was made along the white line of the peritoneum after peritoneal macrophages had been isolated, and the spleen was removed. The spleen was minced with scissors, and the tissue pieces were mashed through a fine sieve into a petri plate containing sterile PBS. The resulting suspension was subjected to Ficoll-Urografin density-gradient centrifugation. The lymphocyte ring was collected into a new test tube. The lymphocytes were washed three times by centrifugation in PBS, $\mathrm{pH} 7.4$, at $750 \times \mathrm{g}$ for $10 \mathrm{~min}$, and the cell pellet was redissolved in $1 \mathrm{ml}$ of PBS. The lymphocytic cells were counted with a HaemaScreenvet hematology analyzer (Hospitex Diagnostics, Italy).
Table 1 Immunization parameters

\begin{tabular}{lllll}
\hline No. & Animals & Antigen construction administered & Amount (ml) & $\begin{array}{l}\text { Dose of protein/peptide } \\
\text { administered }(\mu \mathrm{g})\end{array}$ \\
\hline 1. & Guinea pigs $(n=3)$ & Commercial FMD vaccine & 0.5 & 25 \\
2. & Guinea pigs $(n=3)$ & Au NP-peptide conjugate + CFA $(1: 1)$ & 1 & 6.25 \\
3. & Guinea pigs $(n=3)$ & Au NP-peptide conjugate & 1 & 12.5 \\
4. & Guinea pigs $(n=3)$ & Peptide solution + CFA (1:1) & 1 & 6.25 \\
5. & Guinea pigs $(n=3)$ & $1.7 \mathrm{M} \mathrm{NaCl} \mathrm{solution}$ & 1 & - \\
\hline
\end{tabular}




\section{Analysis of biochemical and immunological parameters}

Sera were biochemically examined with the use of a BA-88A analyzer (Mindray, China) and a standard reagent kit (DiakonDS, Russia). The interleukin concentration in the sera was measured with the use of a Plate Screen analyzer (Hospitex Diagnostics, Italy) and reagent kits for the immunoenzymatic determination of IL-1 $\beta$, IL-6, and IFN- $\gamma$ (Vector-Best, Russia).

The titer of antibodies in the sera was estimated by enzymelinked immunosorbent assay (ELISA) with horseradish peroxidase-labeled antibodies against guinea pig $\operatorname{IgG}$ (Jackson ImmunoResearch, UK). The synthetic peptide was used as the immobilized antigen. The reaction results were recorded on a Plate Screen microplate spectrophotometer. Briefly, the antigen was diluted 1:100 in 0.01 M PBS and incubated overnight at $4{ }^{\circ} \mathrm{C}$. The free binding sites were blocked with $200 \mu \mathrm{l}$ of $2 \%$ fat-free powdered milk in $0.01 \mathrm{M}$ PBS on a shaker for $1 \mathrm{~h}$. Each well then received $100 \mu \mathrm{l}$ of serum from the immunized animals, which was diluted 1:10 in PBS and then serially twofold in PBS. Incubation was done on a thermoshaker at $37{ }^{\circ} \mathrm{C}$ for $1 \mathrm{~h}$. The wells were washed three times for $10 \mathrm{~min}$ each with $200 \mu \mathrm{l}$ of PBS on the shaker, and then, each well received $100 \mu \mathrm{l}$ of horseradish peroxidase-labeled antibodies (Jackson ImmunoResearch, USA) diluted 1:500 in PBS. Incubation was done on the thermoshaker at $37^{\circ} \mathrm{C}$ for $1 \mathrm{~h}$, after which the wells were washed three times for $10 \mathrm{~min}$ each with $200 \mu \mathrm{l}$ of PBS on the shaker. The antigen-antibody reaction was developed with $100 \mu \mathrm{l}$ of $0.006 \% o$ phenylenediamine in $0.1 \mathrm{M}$ sodium citrate buffer containing $0.01 \%$ hydrogen peroxide. The reaction was stopped with $100 \mu \mathrm{l}$ of $0.1 \mathrm{M}$ sulfuric acid.

Respiratory activity was determined conventionally [46] by the ability of cells to reduce nitrotetrazolium blue [3-(4,5dimethylthiazol-2-yl)-2,5-diphenyl tetrazolium bromide (MTT) (Sigma-Aldrich)] to formazan. Briefly, suspensions of known concentrations of isolated animal cells (macrophages and lymphocytes) were centrifuged at $1000 \times g$ for $10 \mathrm{~min}$, and the pellet was resuspended in $1 \mathrm{ml}$ of $0.05 \%$ MTT and incubated at $37{ }^{\circ} \mathrm{C}$ for $1 \mathrm{~h}$. After incubation, the cells were centrifuged at $4000 \times g$ and the pellet was resuspended in $0.5 \mathrm{ml}$ of dimethyl sulfoxide (Fluka, Switzerland). The amount of reduced formazan was measured with a Genesys 10S UV-vis spectrophotometer at $490 \mathrm{~nm}$. To construct the calibration curve, we used commercial formazan (Sigma-Aldrich) at $0.002,0.02,0.2$, and $2 \mathrm{mg} \mathrm{ml}^{-1}$. The concentration of reduced formazan was converted to that per cell.

\section{Dot immunoassay}

The peptide (double dilutions; initial concentration, $1 \mathrm{mg} \mathrm{ml}^{-1}$ ) was applied as a series of spots onto a Western $\mathrm{S}$ polyvinylidene fluoride membrane (Millipore, USA). The membrane was blocked for $1 \mathrm{~h}$ with $2 \%$ fat-free powdered milk diluted in 0.01 M PBS, $\mathrm{pH} 7.2$, dipped into a solution of animal blood serum diluted 100 -fold in $1 \mathrm{ml}$ of $0.01 \mathrm{M}$ PBS, $\mathrm{pH} 7.2$, and incubated at room temperature for $1 \mathrm{~h}$. When there was a biospecific interaction, the serum antibodies bound to the antigen adsorbed on the membrane. The membrane was then washed free of nonspecifically bound antibodies and was immersed in a solution of AuNPs conjugated to staphylococcal protein A $\left(A_{520}=0.5\right)$ (IBPPM, Russia) [43]. After 5$60 \mathrm{~min}$, the binding of the conjugate to the antigen-antibody complex could be observed visually as a series of red spots.

\section{Statistics}

The obtained results were statistically processed by the standard procedures integrated in Excel 2007 software (Microsoft Corp., USA). After the arithmetic mean and the standard deviation for a given data sample had been found, we determined the standard error of the arithmetic mean and its confidence limits with account of Student's $t$ coefficient $(n, p)$ [number of measurements $n=3$, significance level $=95 \%$ $(p=0.05)]$. These results are presented as histograms. The significance of differences between individual samples was evaluated by a two-sample unpaired Student's $t$ test with unequal variances. Differences were considered significant when the experimentally found $p_{\exp }$ value was $\leq 0.05$.

The reliability of the changes recorded in the results of each of the experiments described above for the entire set of antigen formulations examined was assessed by one-way analysis of variance (ANOVA) by using Fisher's ratio test. The dependences found were considered significant at $F>F_{\text {crit }}$, where the critical value $F_{\text {crit }}$ at $n=3$ and $m=4-5$ (number of data sets) corresponded to $p=0.05$ (with the number of degrees of freedom (df) lying between 4 and 14) and the effective value $p_{\text {eff }}$ was $<0.05$.

\section{Results and discussion}

\section{Characterization of AuNPs}

The diameter of the synthesized AuNPs was determined by spectrophotometry (Fig. 1), transmission electron microscopy (TEM; Fig. 2), and dynamic light scattering (DLS; Fig. 2). The absorption spectrum peak of the obtained sol was $\lambda_{\max }=519.1 \mathrm{~nm}$, with the absorbance being $A_{520}=1.2$. As found by TEM and DLS, the average diameter of the obtained nanoparticles was $15.7 \mathrm{~nm}$. The protocol used to prepare AuNPs presupposes that the mass concentration of $\mathrm{Au}$ is constant $\left(58 \mu \mathrm{g}\right.$ per $\mathrm{ml}$ of sol, corresponding to $\left.A_{520}=1\right)$. Therefore, the number of particles per milliliter at $A_{520}=1$ was $1.6 \times 10^{12}$. 


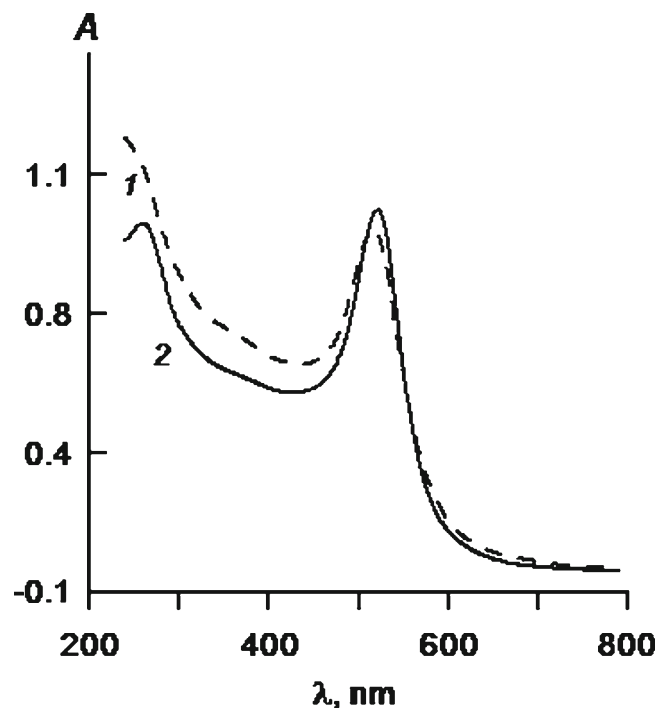

Fig. 1 Absorption spectrum of AuNPs with an average diameter of $15 \mathrm{~nm}$ before (1, broken line) and after (2, solid line) conjugation to the peptide

\section{Evaluation of the humoral response}

For each experiment, the legends to Figs. 3, 5, 6, 7, 8, and 9 give the $p$ value obtained from a pairwise comparison of the corresponding arithmetic mean with the mean characterizing the effect of the commercial FMD vaccine (histogram 1). The bars represent confidence intervals for the arithmetic means. In addition, the legends contain the experimental values of $F$ and $p_{\text {eff }}$ (plus the values of $F_{\text {crit }}$ ) for the sets of experimental data being described.

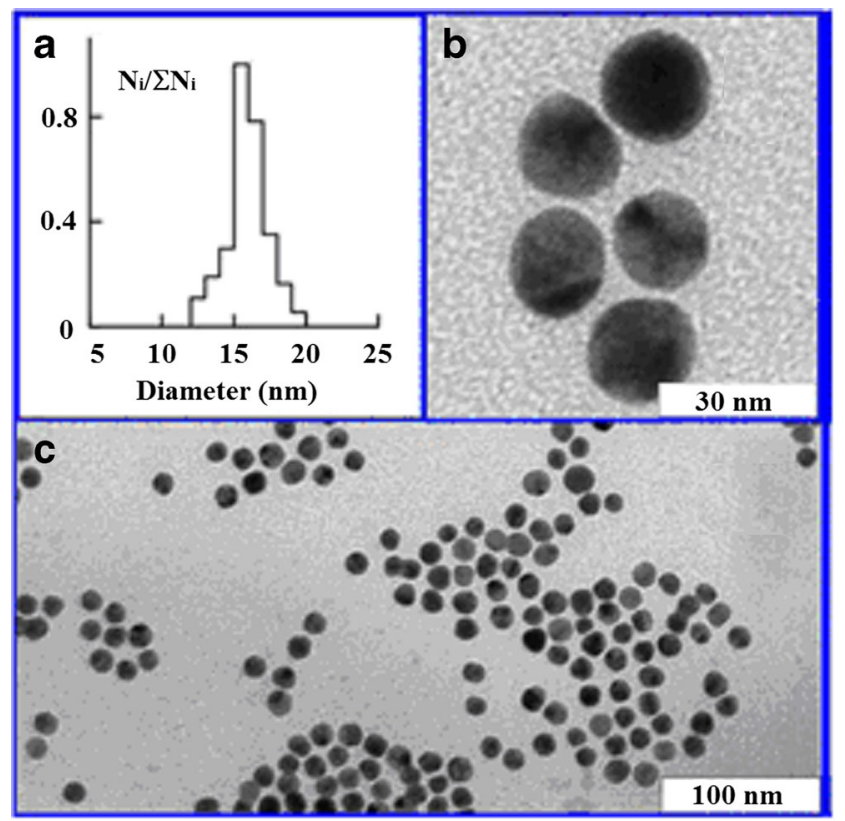

Fig. 2 The number size distribution determined by DLS (a) and TEM images $(\mathbf{b}, \mathbf{c})$ of $15 \mathrm{~nm}$ AuNPs

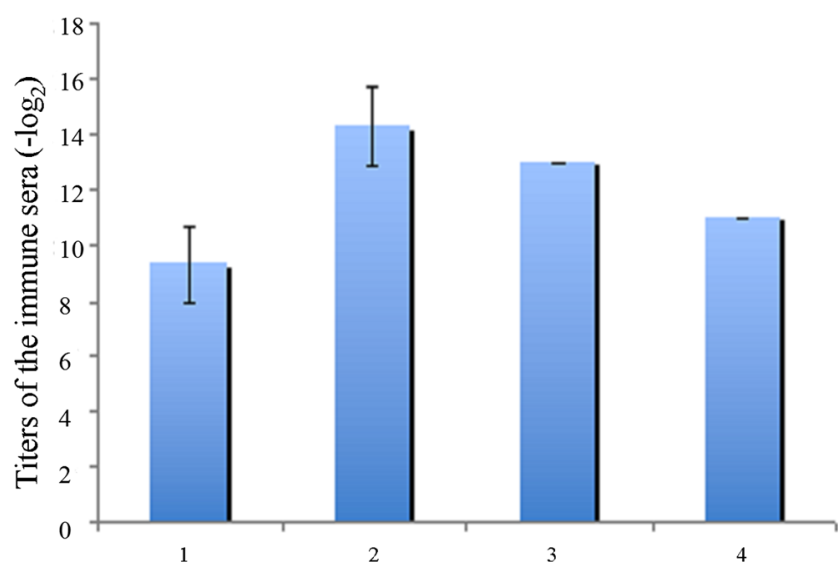

Fig. 3 Effect of the composition of the antigen constructions on the logarithm of the antibody titer: commercial FMD vaccine (1), peptide + AuNPs + CFA (2) $(p=0.00045)$, peptide + AuNPs (3) $(p=0.0081)$, peptide + CFA $(4)(p=0.038) ; F=57.2\left(F_{\text {crit }}=4.12\right), p_{\text {eff }}=2 \times 10^{-5}$

Ten days after the twofold immunization, the titer of the antibodies formed in the blood sera of guinea pigs was determined by ELISA (Fig. 3). The titer of sera from the animals immunized with the AuNP-peptide conjugate plus CFA proved to be the highest $(1 / 32,768)$. It was much higher, with statistical significance, than the titer found for the animals immunized with the commercial vaccine (1/512). In sera from the animals injected with physiological saline, no specific antibodies were detected. The titers of sera from the immunization with the AuNP-peptide conjugate proved to be significantly higher than those found with the native peptide plus CFA.

The immunization of mice with AuNP-FMDV conjugates was described by Chen et al. [26]. In their study, the mice were immunized every week for 9 weeks and throughout the immunization period; only increases in the antibody titers were determined. In this study, by contrast, immunization was conducted twice, and apart from the antibody titer, the production of cytokines and the biochemical parameters of blood serum were examined.

The results of the dot immunoassay of the peptide are shown in Fig. 4. As can be seen, the highest sensitivity was demonstrated by sera from the animals injected with the AuNP-peptide conjugate plus CFA (minimum detectable amount of peptide, $\sim 120 \mathrm{pg}$ ). The sensitivity of sera from the immunization with the AuNP-peptide conjugate was $\sim 31 \mathrm{ng}$, that from the immunization with the peptide solution plus CFA was $\sim 62 \mathrm{ng}$, and that from the immunization with the commercial FMD vaccine was $125 \mathrm{ng}$.

\section{Cytokine production in the sera of immunized animals}

In the process of immunization, we determined the level of production of the proinflammatory cytokines IL-1 $\beta$, IL-6, and IFN- $\gamma$ in sera from the immunized animals (Figs. 5, 6, and 7). It was found that the animals immunized with the AuNP- 


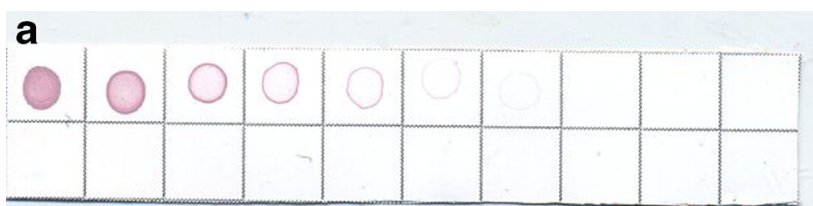

b



C



d

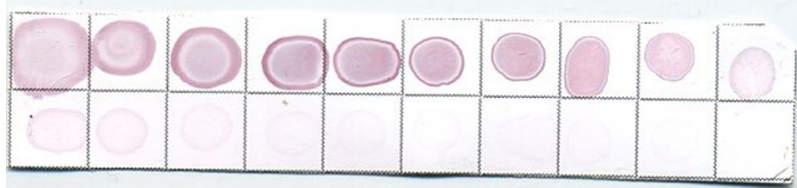

Fig. 4 Dot immunoassay of the peptide (double dilutions; initial concentration, $1 \mathrm{mg} \mathrm{ml}^{-1}$; initial amount, $1 \mu \mathrm{g}$ ) by using sera from immunizations with a AuNP-peptide conjugate, b peptide solution + CFA, c commercial FMD vaccine, and d AuNP-peptide conjugate + CFA. The specific antibodies bound to the antigen were detected with AuNPs conjugated to staphylococcal protein A

peptide conjugate plus CFA produced the largest amounts of the proinflammatory cytokines. The highest increase in production, as compared to the effect obtained from the use of the commercial FMD vaccine $(+62 \%, p=0.0028)$, was observed for IFN- $\gamma$. This finding may indicate that AuNPs conjugated to the viral antigen are able to induce $\mathrm{T}$ lymphocytes and NK

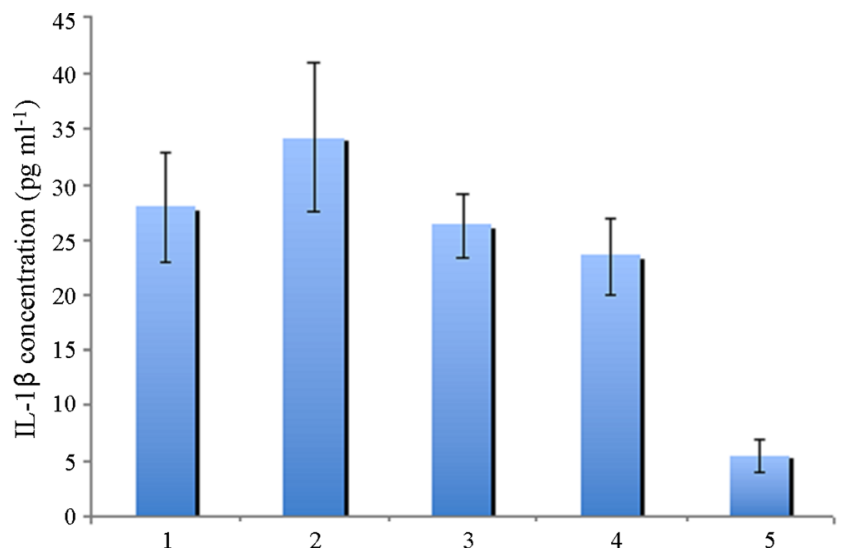

Fig. 5 Effect of the composition of the antigen constructions on the concentration of IL-1 $\beta$ in sera from immunizations with (1) commercial FMD vaccine, $(2)$ peptide + AuNPs + CFA $(p=0.031)$, (3) peptide + AuNPs $(p=0.31)$, and (4) peptide + CFA $(p=0.034)$. Control $(5)(p=$ $0.0028) ; F=117\left(F_{\text {crit }}=3.48\right), p_{\text {eff }}=2 \times 10^{-8}$

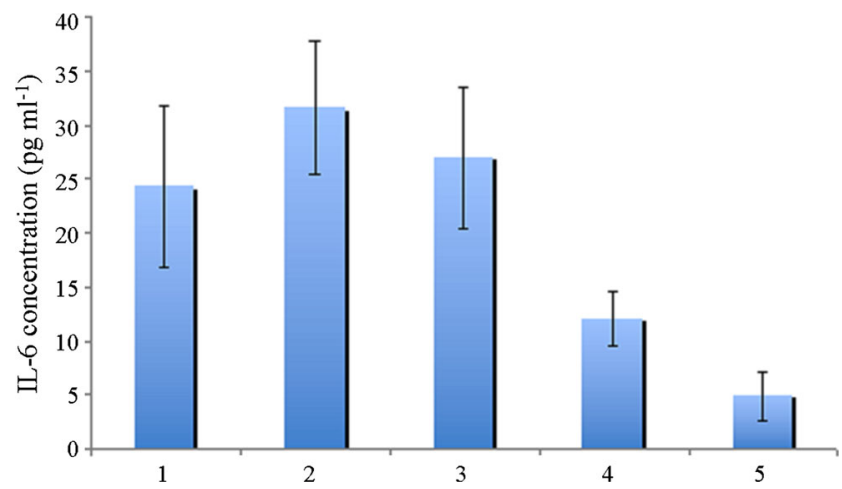

Fig. 6 Effect of the composition of the antigen constructions on the concentration of IL-6 in sera from immunizations with (1) commercial FMD vaccine, $(2)$ peptide + AuNPs + CFA $(p=0.033)$, (3) peptide + AuNPs $(p=0.32)$, and (4) peptide + CFA $(p=0.022)$. Control $(5)(p=$ $0.0088) ; F=76.3\left(F_{\text {crit }}=3.48\right), p_{\text {eff }}=2 \times 10^{-7}$

cells to elaborate IFN- $\gamma$ and trigger a cascade of reactions directed to the immunological regulation of the antiviral immune response. A similar response of the immune system to AuNPs conjugated to a viral antigen was demonstrated earlier $[47,48]$. IFN- $\gamma$, which is a major mediator of inflammation in viral infections, inhibits virus replication in cells, enhances the specific immune response by promoting an increased expression of major histocompatibility complex II, and activates macrophages and NK cells. It is, therefore, probable that AuNPs conjugated to a viral antigen promote a coordinated antiviral immune response.

It should also be noted that all the immunized animals exhibited increased cytokinetic activity. Thus, a significant increase in the concentration of interleukins $1 \beta$ and 6 relative to the control group $(1.7 \mathrm{M} \mathrm{NaCl}$ solution, $p<0.05)$ was observed in all animals that had received the peptide in combination with various immunogens. However, the largest such increase was observed in the animals injected with the AuNPpeptide conjugate plus CFA and the smallest in those injected with the native peptide plus CFA. Because IL- 6 is a factor of B

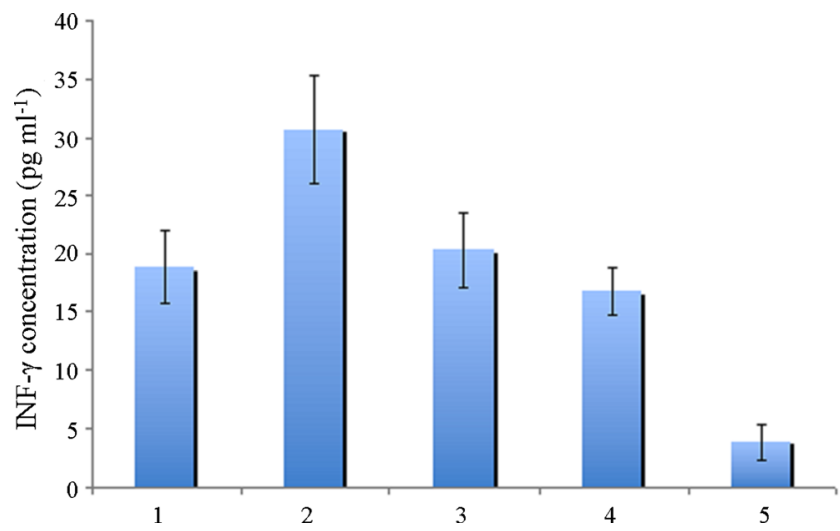

Fig. 7 Effect of the composition of the antigen constructions on the concentration of INF- $\gamma$ in sera from immunizations with (l) commercial FMD vaccine, (2) peptide + AuNPs + CFA $(p=0.0028)$, (3) peptide + AuNPs $(p=0.22)$, and (4) peptide + CFA $(p=0.092)$. Control $(5)(p=$ $0.00032) ; F=180\left(F_{\text {crit }}=3.48\right), p_{\text {eff }}=3 \times 10^{-9}$ 
cell differentiation and promotes the maturation of B lymphocytes into antibody-producing cells, the increase in its concentration may indicate that vaccination with the AuNP-peptide conjugate activated the polyclonal production of Ig.

\section{Respiratory activity of splenic lymphocytes}

Compared with the control (1.7 M NaCl solution), the respiratory activity of splenic lymphocytes increased 3.7-fold ( $p=$ 0.018 ) in the animals immunized with the AuNP-peptide conjugate plus CFA, 2.1-fold $(p=0.015)$ in those immunized with AuNP-peptide conjugate, 2-fold ( $p=0.0016)$ in those immunized with the native antigen plus CFA, and 1.7-fold ( $p=$ 0.00037 ) in those immunized with the commercial vaccine (Fig. 8). This fact may indicate that the antigen constructions being injected create a "depot" at the point of injection, thereby facilitating the extension of the effector phase of the immune response to the administered antigen.

Along with this, the respiratory activity of peritoneal macrophages augmented 2.5 -fold $(p=0.0064)$ in the animals immunized with the AuNP-peptide conjugate plus CFA, 2-fold $(p=0.0045)$ in those immunized with the AuNP-peptide conjugate, 1.5 -fold $(p=0.005)$ in those immunized with the native antigen plus CFA, and 1.4-fold $(p=0.0059)$ in those immunized with the commercial vaccine (Fig. 9). This is consistent with the previous findings that AuNPs in complex with highand low-molecular-weight antigens stimulate the respiratory activity of peritoneal macrophages [48].

\section{General remarks}

Thus, for all the experiments depicted in Figs. 3, 5, 6, 7, 8, and 9, comparison of the effect of the AuNP-peptide conjugate plus CFA and that of the commercial FMD vaccine shows that

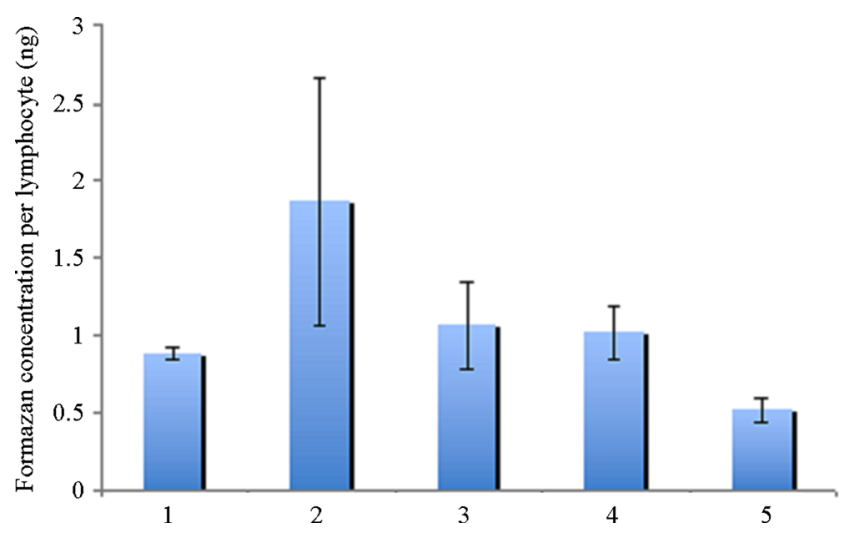

Fig. 8 Effect of the composition of the antigen constructions on the respiratory activity of splenic lymphocytes: (1) commercial FMD vaccine, (2) peptide + AuNPs + CFA $(p=0.034)$, (3) peptide + AuNPs $(p=0.11)$, and (4) peptide + CFA $(p=0.084)$. Control $(5)(p=0.00037)$; $F=30\left(F_{\text {crit }}=3.48\right), p_{\text {eff }}=1.5 \times 10^{-5}$

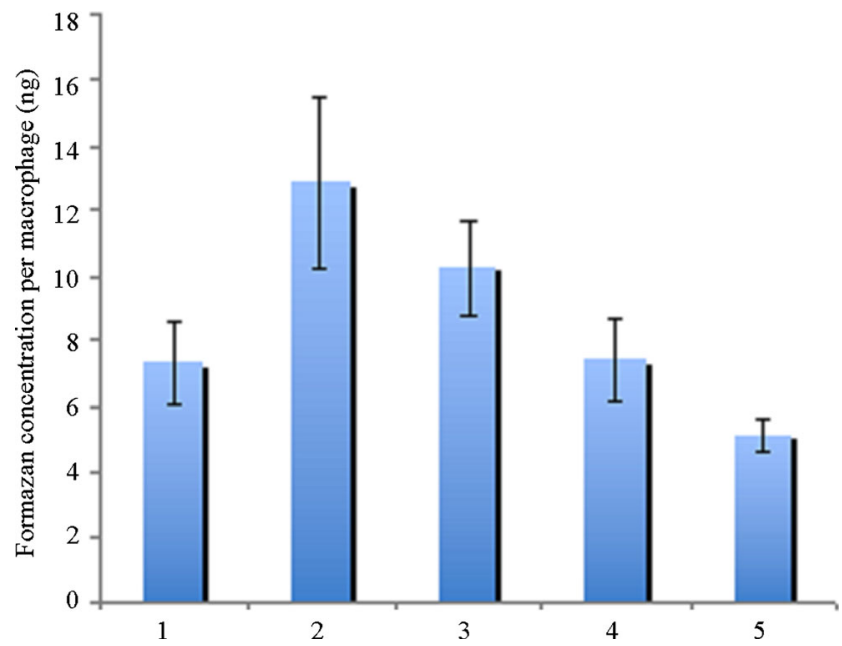

Fig. 9 Effect of the composition of the antigen constructions on the respiratory activity of peritoneal macrophages: (1) commercial FMD vaccine, $(2)$ peptide + AuNPs + CFA $(p=0.0039)$, (3) peptide + AuNPs $(p=0.0027)$, and (4) peptide + CFA $(p=0.82)$. Control $(5)(p=0.0059)$; $F=67.8\left(F_{\text {crit }}=3.48\right), p_{\text {eff }}=3 \times 10^{-7}$

the corresponding parameters increased from +23 to $+110 \%$ with statistical significance $(p<0.05)$. In all the experiments, the use of the AuNP-peptide conjugate without CFA resulted in an effect comparable to (Figs. 3, 5, 6, 7, 8, and 9) or significantly greater than (by about $40 \%$; Figs. 3 and 9) that of the commercial FMD vaccine.

The ANOVA results (the values of $F, F_{\text {crit }}$ and $p_{\text {eff }}$ given in the legends to Figs. 3, 5, 6, 7, 8, and 9) also attest that the observed relationship between the immunological parameters and the composition of the antigen constructions had high statistical significance.

The data available on the safety of AuNPs in vivo (especially when these are administered subcutaneously) are few and conflicting. Nevertheless, it can be considered proven that a rapid decrease in the concentration of nanoparticles in blood and their long-term retaining in the animal body is related to the functioning of the hepatobiliar system. As the excretion of accumulated particles from the liver and spleen can take up to 3 to 4 months, the question as to the injected doses and possible inflammation processes is still of great importance. At present, one can only assume that if AuNPs are administered for a brief time (about a week) at a daily dose not exceeding $0.5 \mathrm{mg} \mathrm{kg}^{-1}$, no appreciable toxicity results [49]. In our experiments, the injected dose and the period of administration were inherently smaller than those.

In a biochemical study of guinea pig blood serum, we found no significant differences between the corresponding parameters for the antigen constructions used, as compared with the effect of the commercial FMD vaccine and with the control. This result indirectly indicates that the administered Au-containing antigen constructions were not toxic to the basic physiological functions of the animals. 


\section{Conclusions}

The data generated by this study characterize the effect of AuNPs on the immune response of the guinea pigs immunized with a synthetic peptide of the $\mathrm{VP}_{1}$ capsid protein of the FMDV, as compared to the responses obtained from the animals immunized with a commercial FMD vaccine and with the native peptide. It has been established that the AuNPpeptide conjugate mixed with CFA induced a much more pronounced immune response than did the other antigen constructions. This was manifested by a significantly higher titer of antibodies produced and by their higher sensitivity shown in an immunoassay of the antigen. Antibody biosynthesis was accompanied by considerably increased production of proinflammatory cytokines (especially IFN- $\gamma$ ) and by stimulation of the respiratory activity of peritoneal macrophages. That there were almost no significant differences between the effects of the Au-containing antigen constructions and the commercial FMD vaccine on one hand and the results of the control experiments in the biochemical study of blood serum on the other indirectly indicates that the administered antigen constructions were not toxic to the basic physiological functions of the guinea pigs.

In all the experiments, the use of the AuNP-peptide conjugate without CFA resulted in an effect comparable to or significantly greater than that of the commercial FMD vaccine. This finding suggests that AuNPs might serve as a single adjuvant in the future work on designing peptide vaccines. In addition, we believe that the use of a synthetic peptide in vaccination will cause no residual infectivity.

In summary, our present results create a basis for further research on the resistance of vaccinated animals to FMD, with a view to developing a single-use nanovaccine against FMD.

Acknowledgments This study was supported by the Russian Scientific Foundation (grant no. 15-14-00002). We thank Mr. Dmitry N. Tychinin for his help in preparation of the manuscript.

Open Access This article is distributed under the terms of the Creative Commons Attribution 4.0 International License (http://creativecommons.org/licenses/by/4.0/), which permits unrestricted use, distribution, and reproduction in any medium, provided you give appropriate credit to the original author(s) and the source, provide a link to the Creative Commons license, and indicate if changes were made.

\section{References}

1. Martinez-Salas E, Saiz M, Sobrino F (2008) Foot-and-mouth disease virus. In: Mettenleiter TC, Sobrino F (eds) Animal Viruses: Molecular Biology. Caister Academic Press, Norfolk, pp 1-38

2. Doel TR (1996) Natural and vaccine-induced immunity to foot and mouth disease: the prospects for improved vaccines. Rev Sci Tech $15: 883-911$
3. Barret ADT, Stanberry LR (2009) Vaccines for biodefense and emerging and neglected diseases. Elsevier Academic Press, Amsterdam

4. Park J-H (2013) Requirements for improved vaccines against footand-mouth disease epidemics. Clin Exp Vaccine Res 2:8-18. doi: 10.7774/cevr.2013.2.1.8

5. Barteling SJ, Cassim NI (2004) Very fast (and safe) inactivation of foot-and-mouth disease virus and enteroviruses by a combination of binary ethyleneimine and formaldehyde. Dev Biol (Basel) 119: 449-455

6. Korobko VG, Boldyreva EF, Nekrasova OV, Mikulskis A, Filippov SA, Dobrynin VN (1991) Synthesis, cloning and expression of artificial genes coding for antigenic determinants of the foot-andmouth disease virus strain $\mathrm{A}_{22}$. Russ J Bioorg Chem 17:461-469

7. Bloom BR, Lambert P-H (2003) The vaccine book. Academic Press, San Diego

8. Moisa AA, Kolesanova EF (2010) Synthetic peptide vaccines. Biochem (Moscow) Suppl Ser B Biomed Chem 4:321-332. doi: 10.1134/s1990750810040025

9. Tekleghiorghis T, Weerdmeester K, van Hemert-Kluitenberg F, Moormann RJM, Dekker A (2014) No significant differences in the breadth of the foot-and-mouth disease serotype A vaccine induced antibody responses in cattle, using different adjuvants, mixed antigens and different routes of administration. Vaccine 32:5330 5336. doi:10.1016/j.vaccine.2014.07.033

10. Bittle JL, Houghten RA, Alexander H, Shinnick TM, Sutcliffe JG, Lerner RA, Rowlands DJ, Brown F (1982) Protection against footand-mouth disease by immunization with a chemically synthesized peptide predicted from the viral nucleotide sequence. Nature 298: 30-33. doi:10.1038/298030a0

11. Strohmaier K, Franze R, Adam KH (1982) Location and characterization of the antigenic portion of the FMDV immunizing protein. $\mathrm{J}$ Gen Virol 59:295-306. doi:10.1099/0022-1317-59-2-295

12. Volpina OM, Yarov AV, Zhmak MN, Kuprianova MA, Chepurkin AV, Toloknov AS, Ivanov VT (1996) Synthetic vaccine against foot-and-mouth disease based on a palmitoyl derivative of the $\mathrm{VP}_{1}$ protein 135-159 fragment of the $\mathrm{A}_{22}$ virus strain. Vaccine 14: 1375-1380. doi:10.1016/S0264-410X(96)00038-2

13. Volpina OM, Surovoy AY, Zhmak MN, Kuprianova MA, Koroev DO, Chepurkin AV, Toloknov AS, Ivanov VT (1999) A peptide construct containing B-cell and T-cell epitopes from the foot-andmouth disease viral $\mathrm{VP}_{1}$ protein induces efficient antiviral protection. Vaccine 17:577-584. doi:10.1016/S0264-410X(98)00236-9

14. Kuprianova MA, Zhmak MN, Koroev DO, Chepurkin AV, Volpina OM, Ivanov VT (2000) Synthetic peptide constructs on the basis of immunoactive fragments of the $\mathrm{A}_{22}$ strain $\mathrm{VP}_{1}$ of the foot-andmouth disease virus. Russ J Bioorg Chem 26:832-837. doi:10. 1023/A:1026614622241

15. Dobrovolskaia MA, McNeil SE (2013) Handbook of immunological properties of engineered nanomaterials. World Scientific Publ, Singapore

16. Zaman M, Good MF, Toth I (2013) Nanovaccines and their mode of action. Methods 60:226-231. doi:10.1016/j.ymeth.2013.04.014

17. Zhao L, Seth A, Wibowo N, Zhao C-X, Mitter N, Yu C, Middelberg AP (2014) Nanoparticle vaccines. Vaccine 32:327-337. doi:10. 1016/j.vaccine.2013.11.069

18. Liu Y, Xu Y, Tian Y, Chen C, Wang C, Jiang X (2014) Functional nanomaterials can optimize the efficacy of vaccines. Small 10 : 4505-4520. doi:10.1002/smll.201401707

19. Prashant CK, Kumar M, Dinda AK (2014) Nanoparticle based tailoring of adjuvant function: the role in vaccine development. $\mathrm{J}$ Biomed Nanotechnol 10:2317-2331. doi:10.1166/jbn.2014.1991

20. Shiosaka S, Kiyama H, Wanaka A, Tohyama M (1986) A new method for producing a specific and high titre antibody against glutamate using colloidal gold as a carrier. Brain Res 382:399 403, 10.1016/0006-8993(86)91352-1 
21. Chen Y-S, Hung Y-C, Lin W-H, Huang GS (2010) Assessment of gold nanoparticles as a size-dependent vaccine carrier for enhancing the antibody response against synthetic foot-and-mouth disease virus peptide. Nanotechnology 21:195101. doi:10.1088/0957-4484/ 21/19/195101

22. Dykman LA, Khlebtsov NG (2012) Gold nanoparticles in biomedical applications: recent advances and perspectives. Chem Soc Rev 41:2256-2282. doi:10.1039/C1CS15166E

23. Dykman LA, Sumaroka MV, Staroverov SA, Zaitseva IS, Bogatyrev VA (2004) Immunogenic properties of colloidal gold. Biol Bull 31:75-79. doi:10.1023/B:BIBU.0000014358.98422.9c

24. Dykman LA, Staroverov SA, Bogatyrev VA, Shchyogolev SY (2010) Adjuvant properties of gold nanoparticles. Nanotechnol Russia 5:748-761. doi:10.1134/S1995078010110029

25. Demenev VA, Shchinova MA, Ivanov LI, Vorobeva RN, Zdanovskaia NI, Nebaikina NV (1996) Perfection of methodical approaches to designing vaccines against tick-borne encephalitis. Vopr Virusol 41:107-110 (in Russian)

26. Chen Y-S, Hung Y-C, Liau I, Huang GS (2009) Assessment of the in vivo toxicity of gold nanoparticles. Nanoscale Res Lett 4:858864. doi:10.1007/s11671-009-9334-6

27. Tao W, Ziemer KS, Gill HS (2014) Gold nanoparticle-M2e conjugate coformulated with $\mathrm{CpG}$ induces protective immunity against influenza A virus. Nanomedicine (London) 9:237-251. doi:10. 2217/nnm.13.58

28. Staroverov SA, Vidyasheva IV, Gabalov KP, Vasilenko OA, Laskavyi VN, Dykman LA (2011) Immunostimulatory effect of gold nanoparticles conjugated with transmissible gastroenteritis virus. Bull Exp Biol Med 151:436-439. doi:10.1007/s10517-011$1350-8$

29. Niikura K, Matsunaga T, Suzuki T, Kobayashi S, Yamaguchi H, Orba Y, Kawaguchi A, Hasegawa H, Kajino K, Ninomiya T, Ijiro K, Sawa H (2013) Gold nanoparticles as a vaccine platform: influence of size and shape on immunological responses in vitro and in vivo. ACS Nano 7:3926-3938. doi:10.1021/nn3057005

30. Stone JW, Thornburg NJ, Blum DL, Kuhn SJ, Wright DW, Crowe JE Jr (2013) Gold nanorod vaccine for respiratory syncytial virus. Nanotechnology 24:295102. doi:10.1088/0957-4484/24/29/ 295102

31. Dykman LA, Staroverov SA, Bogatyrev VA, Shchyogolev SY (2010) Gold nanoparticles as an antigen carrier and an adjuvant. Nova Science Publishers, New York

32. Staroverov SA, Dykman LA (2013) Use of gold nanoparticles for the preparation of antibodies to tuberculin, the immunoassay of mycobacteria, and animal vaccination. Nanotechnol Russia 8: 816-822. doi:10.1134/S1995078013060165

33. Manea F, Bindoli C, Fallarini S, Lombardi G, Polito L, Lay L, Bonomi R, Mancin F, Scrimin P (2008) Multivalent, saccharidefunctionalized gold nanoparticles as fully synthetic analogs of type A Neisseria meningitidis antigens. Adv Mater 20:4348-4352. doi: 10.1002/adma.200800737

34. Gregory AE, Williamson ED, Prior JL, Butcher WA, Thompson IJ, Shaw AM, Titball RW (2012) Conjugation of Y. pestis F1-antigen to gold nanoparticles improves immunogenicity. Vaccine 30:67776782. doi:10.1016/j.vaccine.2012.09.021
35. Safari D, Marradi M, Chiodo F, Dekker HAT, Shan Y, Adamo R, Oscarson S, Rijkers GT, Lahmann M, Kamerling JP, Penadés S, Snippe H (2012) Gold nanoparticles as carriers for a synthetic Streptococcus pneumoniae type 14 conjugate vaccine. Nanomedicine (London) 5:651-662. doi:10.2217/nnm.11.151

36. Gregory AE, Judy BM, Qazi O, Blumentritt CA, Brown KA, Shaw AM, Torres AG, Titball RW (2015) A gold nanoparticle-linked glycoconjugate vaccine against Burkholderia mallei. Nanomedicine 11:447-456. doi:10.1016/j.nano.2014.08.005

37. Gao W, Fang RH, Thamphiwatana S, Luk BT, Li J, Angsantikul P, Zhang Q, Hu C-MJ, Zhang L (2015) Modulating antibacterial immunity via bacterial membrane-coated nanoparticles. Nano Lett 15 : 1403-1409. doi:10.1021/nl504798g

38. Almeida JPM, Figueroa ER, Drezek RA (2013) Gold nanoparticle mediated cancer immunotherapy. Nanomedicine 10:503-514. doi: 10.1016/j.nano.2013.09.011

39. Cao-Milán R, Liz-Marzán LM (2014) Gold nanoparticle conjugates: recent advances toward clinical applications. Expert Opin Drug Deliv 11:741-752. doi:10.1517/17425247.2014.891582

40. Lowry OH, Rosebrough NJ, Farr AL, Randall RJ (1951) Protein measurement with the Folin phenol reagent. J Biol Chem 193:265275

41. Frens G (1973) Controlled nucleation for the regulation of the particle size in monodisperse gold suspensions. Nature Phys Sci 241: 20-22. doi:10.1038/physci241020a0

42. Khlebtsov NG, Dykman LA (2010) Optical properties and biomedical applications of plasmonic nanoparticles. J Quant Spectrosc Radiat Transf 111:1-35. doi:10.1016/j.jqsrt.2009.07.012

43. Dykman LA, Bogatyrev VA, Shchyogolev SY, Khlebtsov NG (2008) Gold nanoparticles: synthesis, properties, biomedical applications. Nauka, Moscow (in Russian)

44. Tao W, Gill HS (2015) M2e-immobilized gold nanoparticles as influenza A vaccine: role of soluble M2e and longevity of protection. Vaccine 33:2307-2315. doi:10.1016/j.vaccine.2015.03.063

45. Leiter EH (2001) The NOD mouse: a model for insulin dependent diabetes mellitus. In: Coligan JE, Kruisbeek AM, Margulies DH, Shevach EM, Strober W (eds) Current Protocols in Immunology. John Wiley \& Sons, New York, pp 15.9.1-15.9.23

46. Bernas T, Dobrucki JW (2000) The role of plasma membrane in bioreduction of two tetrazolium salts, MTT, and CTC. Arch Biochem Biophys 380:108-116. doi:10.1006/abbi.2000.1907

47. Cheung W-H, Chan VS-F, Pang H-W, Wong M-K, Guo Z-H, Tam PK-H, Che C-M, Lin C-L, Yu W-Y (2009) Conjugation of latent membrane protein (LMP)-2 epitope to gold nanoparticles as highly immunogenic multiple antigenic peptides for induction of EpsteinBarr virus-specific cytotoxic T-lymphocyte responses in vitro. Bioconjug Chem 20:24-31. doi:10.1021/bc800167q

48. Staroverov SA, Aksinenko NM, Gabalov KP, Vasilenko OA, Vidyasheva IV, Shchyogolev SY, Dykman LA (2009) Effect of gold nanoparticles on the respiratory activity of peritoneal macrophages. Gold Bull 42:153-156. doi:10.1007/BF03214925

49. Khlebtsov NG, Dykman LA (2011) Biodistribution and toxicity of engineered gold nanoparticles: a review of in vitro and in vivo studies. Chem Soc Rev 40:1647-1671. doi:10.1039/c0cs00018c 